\title{
Announcement of the Fulker Award for a Paper Published in Behavior Genetics, Volume 44, 2014
}

The Fulker Award was established by the Behavior Genetics Association in memory of David Fulker, a past President the Association and Executive Editor of the journal, who died in 1998 (Hewitt 1998). The award is for 'a particularly meritorious paper' published in the journal during the preceding year. The annual prize is $\$ 1000$ 'and a nice bottle of wine' (given only when the recipient is present at the Association's annual meeting.)

Volume 44 included 54 rigorously peer reviewed papers on human and animal behavior genetics. To select the paper for the Fulker award, I solicit nominations from the journal's Associate Editors and follow their advice closely.

Among the outstanding papers nominated by the editors were: a paper by Conor Dolan and colleagues (2014) on GE covariance through phenotype to environment transmission, exploring the consequences of such transmission during development; by Pete Hatemi and colleagues (2014) reporting twin analyses and genome wide association studies of political ideologies, showing substantial heritability and, no surprise here, no genome wide significant SNPs; and by Matt McGue and colleagues (2014) reporting parent-offspring similarity for drinking in a longitudinal adoption study that suggested increasing genetic influences and decreasing family environment as offspring transition into late adolescence and early adulthood.

But the paper that most impressed the Associate Editors was by this year's winners: Lindon Eaves and colleagues (2014) who developed an extension of genome wide complex trait analysis-GCTA - to include environmental effects of maternal genotype on offspring phenotype-M-GCTA or maternal effects GCTA. This novel extension was tested by both simulation and application to illustrative data on maternal height (expected to be influenced by maternal genotype but not by offspring genotype), and offspring birth length (expected to be influenced by both maternal and offspring genotype). The overall pattern of the model fitting results was consistent with these expectations. Importantly, the paper demonstrates that normal GCTA will produce biased results in the presence of such things as maternal effects. As Lindon Eaves, in his inimitable way, said it in the title of a talk on this work last year at IBG; "Just because you can measure genes doesn't mean you can leave your brain behind".

So congratulations to Lindon Eaves, Beate Pourcain, George Davey Smith, Tim York, and David Evans for their Fulker Award winning paper: Resolving the effects of maternal and offspring genotype on dyadic outcomes in genome wide complex trait analysis ("M-GCTA").

John K. Hewitt
Editor-in-Chief

\section{References}

Dolan CV, de Kort JM, van Beijsterveldt TC, Bartels M, Boomsma DI (2014) GE covariance through phenotype to environment transmission: an assessment in longitudinal twin data and application to childhood anxiety. Behav Genet 44(3):240-253

Eaves LJ, Pourcain BS, Smith GD, York TP, Evans DM (2014) Resolving the effects of maternal and offspring genotype on dyadic outcomes in genome wide complex trait analysis ("MGCTA”). Behav Genet 44(5):445-455

Hatemi PK, Medland SE, Klemmensen R, Oskarsson S, Littvay L, Dawes CT, Verhulst B, McDermott R, Nørgaard AS, Klofstad CA, Christensen K, Johannesson M, Magnusson PK, Eaves LJ, Martin NG (2014) Genetic influences on political ideologies: twin analyses of 19 measures of political ideologies from five democracies and genome-wide findings from three populations. Behav Genet. 44(3):282-294

Hewitt JK (1998) David William Fulker (1937-1998). Behav Genet 28(4):239-241

McGue M, Malone S, Keyes M, Iacono WG (2014) Parent-offspring similarity for drinking: a longitudinal adoption study. Behav Genet 44(6):620-628 